\title{
Revisão taxonômica de Myrocarpus Allemão (Leguminosae, Papilionoideae, Sophoreae) ${ }^{1}$
}

\author{
Ângela L.B. Sartori ${ }^{2,4}$ e Ana Maria G. de Azevedo Tozzi ${ }^{3}$
}

Recebido em 20/09/2001. Aceito em 14/01/2004

\begin{abstract}
RESUMO - (Revisão taxonômica de Myrocarpus Allemão (Leguminosae, Papilionoideae, Sophoreae)). Em Myrocarpus, gênero exclusivamente sul-americano, são reconhecidas cinco espécies: Myrocarpus frondosus Allemão, M. leprosus Pickel, M. venezuelensis Rudd, M. fastigiatus Allemão e M. emarginatus A.L.B. Sartori \& A.M.G. Azevedo. Na delimitação das espécies são discutidos dados de morfologia, hábitats e de distribuição geográfica. A morfologia das pétalas e a ornamentação da região seminífera são caracteres relevantes na identificação das espécies, embora não utilizados até o presente. Este estudo apresenta chave de identificação das espécies, descrições, ilustrações, mapa de distribuição e novos registros de ocorrência.
\end{abstract}

Palavras-chave: Myrocarpus, Sophoreae, Papilionoideae, Leguminosae, taxonomia

ABSTRACT - (Taxonomic revision of Myrocarpus Allemão (Leguminosae, Papilionoideae, Sophoreae)). In Myrocarpus, an exclusively South American genus, five species are recognised: Myrocarpus frondosus Allemão, M. leprosus Pickel, M. venezuelensis Rudd, M. fastigiatus Allemão and M. emarginatus A.L.B. Sartori \& A.M.G. Azevedo. Morphologic data, habitat information and geographic distribution of each taxon are discussed. Petal morphology and ornamentation of seed chamber are an important character for species identification, though not shown previously. Key to the species, descriptions, illustrations, distribution, and new registers are presented.

Key words: Myrocarpus, Sophoreae, Papilionoideae, Leguminosae, taxonomy

\section{Introdução}

Myrocarpus Allemão está subordinado às Sophoreae, tribo que integra elementos com caracteres intermediários entre Papilionoideae e Caesalpinioideae. Segundo Polhill (1994), a tribo está constituída por 46 gêneros e cerca de 370 espécies, distribuídos em grupos informais conforme o grau de especialização das flores. Assim, em seus integrantes podem ser verificadas flores regulares até zigomorfas.

Myrocarpus foi descrito por Allemão (1847) baseado na presença de flor regular, embrião reto e ocorrência de bálsamo no fruto. O nome é uma alusão à presença de bálsamo no fruto, conforme implícito no prefixo grego "Myron", que significa óleo perfumado (Stearn 1973). Foram estabelecidos seis binômios (Rudd 1972; Polhill 1981; Lewis 1987; Sartori \& Tozzi 2001), mas somente cinco espécies têm sido aceitas (Rudd 1972; Sartori \& Tozzi 2001). O único estudo taxonômico enfocando o gênero (Rudd 1972) foi baseado, principalmente, em coleções dos tipos e/ou na avaliação de poucos espécimes herborizados, dificultando análise da variação morfológica, da distribuição geográfica, bem como dos ambientes preferenciais das espécies. Lewis (1987) sugeriu a necessidade de análise detalhada da circunscrição de $M$. fastigiatus, com base em sua relutância na identificação dos espécimes por ele analisados. O esclarecimento dos limites intragenéricos de Myrocarpus é importante para organizar o conhecimento sobre as especializações morfológicas, considerando não somente o posicionamento estratégico do gênero em Sophoreae, mas também entre Papilionoideae e Caesalpinioideae. Este assunto tem sido objeto de estudos e discussões como evidenciado por Pennington et al. (2000).

Myrocarpus figura como um grupo exclusivamente sul-americano, com representantes no Paraguai, na Venezuela, na Bolívia e no Brasil, sendo que o maior número de espécies ocorre em território brasileiro (Rudd 1972; Lewis 1987).

Visando conhecer a morfologia das espécies de Myrocarpus e avaliar o potencial diagnóstico de novos

\footnotetext{
Parte da Tese de Doutorado da primeira Autora

2 CCBS/ DBI, Botânica, Universidade Federal do Mato Grosso do Sul, C. Postal 549, CEP 79070-900, Campo Grande, MS, Brasil

3 Departamento de Botânica, Instituto de Biologia, Universidade Estadual de Campinas, C. Postal 6109, CEP 13083-970, Campinas, SP, Brasil

4 Autora para correspondência: angela.sartori@uol.com.br
} 
caracteres macromorfológicos, o presente estudo teve como objetivos realizar a revisão taxonômica de Myrocarpus, fornecer chave de identificação, descrições, ilustrações, datas de floração e frutificação e informações atualizadas sobre a distribuição geográfica das espécies.

\section{Material e métodos}

O presente estudo foi baseado na análise de espécimes coletados e de material herborizado proveniente dos herbários: B, BA, BHCB, BM, C, CEPEC, CR, CVRD, ESA, F, FUEL, G, HUEFS, INPA, M, MEXU, MO, NY, PEUFR, R, RB, S, SP, SPF, U, UEC, US, VEN, VIC, VIES (siglas de acordo com Holmgren et al. 1990).

As abreviações das obras príncipes estão baseadas em Lawrence et al. (1971) e Bridson \& Smith (1991). A avaliação dos procedimentos taxonômicos e da tipificação foi fundamentada em Greuter et al. (1994). Coleções sintípicas foram lectotipificadas.

$\mathrm{Na}$ análise morfológica foram adotados os procedimentos convencionais em taxonomia. Foram considerados aproximadamente 40 caracteres compreendendo os vegetativos e os reprodutivos, sendo padronizadas as mensurações para folíolos subterminais e flores em pré-antese. Para cada espécie o mínimo de 20 espécimes foi analisado, exceto para aquelas com quantidade reduzida de material disponível. A terminologia utilizada para morfologia foliolar, tipos de inflorescência e de revestimento foi baseada em Lawrence (1971) e Radford et al. (1974) e a ornamentação da semente, em Stearn (1973). O termo lacínio está sendo utilizado para designar a porção livre das sépalas, e o comprimento do cálice inclui o hipanto.

Os dados de distribuição geográfica, hábitats e nomes populares foram obtidos das etiquetas das exsicatas. Para a confecção do mapa de distribuição das espécies, as coordenadas foram registradas em planilhas do programa Microsoft Excell e processadas pelo programa Versamap 2.03. A terminologia adotada para a vegetação foi baseada em Veloso (1992).

\section{Resultados e discussão}

Myrocarpus Allemão, Diss. Leg. 26, com ícone, 1847.

\section{Tipo: M. fastigiatus Allemão}

Árvores, ramos cilíndricos ou quadrangulares, estípulas caducas. Folhas imparipinadas, até 12-folioladas; pecíolo dorsiventralmente achatado; raque quadrangular, sulcada adaxialmente; folíolos alternos, venação broquidódroma, pontos e listras translúcidos na lâmina. Racemos simples, geminados, fasciculados, axilares ou terminais, às vezes em ramos áfilos; brácteas deltóides ou lineares, na base do pedicelo; hipanto presente, externamente delimitado por sulcos longitudinais; bractéolas na região basal do hipanto, diminutas, caducas; flores regulares, pentâmeras, pediceladas; cálice campanulado, lacínios cinco, prefloração valvar; pétalas semelhantes entre si; androceu com dez estames, glabros, filetes iguais ou de duas alturas diferentes, fundidos na base, anteras dorsifixas, elípticas, ápice e base obtusos, deiscência rimosa; gineceu 3-5-ovulado, seríceo ou glabro, estipitado, estigma truncado ou puntiforme. Sâmara com 3-5 sementes, ala marginal, região seminífera central, escalariforme ou areolada.

Hábito - Os representantes de Myrocarpus geralmente são árvores de grande porte com os indivíduos ultrapassando $20 \mathrm{~m}$ alt., como verificado em M. frondosus, $M$. venezuelensis e menos freqüentemente em $M$. fastigiatus. Em M. leprosus e M. emarginatus são de menor porte, não ultrapassando $10 \mathrm{~m}$ alt. Os ramos, em secção transversal, podem variar de cilíndricos a quadrangulares. As espécies que apresentam somente ramos cilíndricos compreendem $M$. leprosus, $M$. venezuelensis e $M$. fastigiatus. Ramos cilíndricos e quadrangulares são verificados em $M$. frondosus e quadrangulares em $M$. emarginatus.

Folha - As folhas são imparipinadas, com as estípulas caducas, apresentam pecíolo achatado dorsiventralmente e a raque sulcada adaxialmente. Os folíolos são geralmente alternos, com venação broquidódroma e margem inteira. O tipo de margem crenado, verificado, por exemplo, em $M$. frondosus, ocorre nos folíolos jovens, desaparecendo naqueles bem desenvolvidos. Os folíolos são elípticos, ovais ou oblongos. O ápice é acuminado em $M$. frondosus, M. leprosus e M. venezuelensis. Ápice longamente acuminado também pode ser encontrado em $M$. venezuelensis, com acúmen de comprimento superior a $4 \mathrm{~mm}$. Folíolos de ápice obtuso, retuso ou emarginado podem ser observados em $M$. fastigiatus, M. emarginatus. A base dos folíolos pode variar de atenuada, oblíqua, arredondada e menos comumente subcordada. Nos representantes de Myrocarpus pontos e listras translúcidos são conspícuos na lâmina foliolar, exceto em $M$. leprosus onde são menos evidentes. Os folíolos, de um modo geral, são 
glabrescentes e opacos em ambas as superfícies, exceto em $M$. venezuelensis com a superfície adaxial brilhante. O tipo de inflorescência é o racemo, com algumas variações. Racemos simples menores que as folhas são encontrados em M. fastigiatus e $M$. leprosus. Racemos simples e geminados, menores ou maiores que as folhas são verificados em M. frondosus. Algumas espécies apresentam caducifolia facultativa, pois se tornam áfilas nos períodos reprodutivos, como é o caso de M. frondosus e M. fastigiatus. As brácteas comumente estão posicionadas na base do pedicelo e possuem até $1 \mathrm{~mm}$ compr.; são deltóides em $M$. frondosus e em M. leprosus e lineares em M. fastigiatus. As flores são pediceladas (Fig. 1-4), geralmente com pedicelo de até $1,5 \mathrm{~mm}$ compr. O hipanto em Myrocarpus pode atingir ca. $2,5 \mathrm{~mm}$ compr. e externamente pode apresentar uma constrição abaixo do cálice (Fig. 4), relacionada à região apical do mesmo e onde se inserem os filetes e as pétalas. O cálice é campanulado com os lacínios superficialmente diferenciados (Fig. 5-8). É constatada a ocorrência de diferentes tipos de tricomas que revestem o cálice. Indumento seríceo ocorre em $M$. frondosus e M. leprosus e tomentoso em M. fastigiatus. A morfologia floral permite o reconhecimento de formas distintas de pétalas e consiste em uma importante característica para a delimitação de suas espécies. Myrocarpus apresenta flores regulares com todas as pétalas semelhantes (Fig. 9-12), branco-esverdeadas em M. frondosus e amarelo-claro ou brancas em M. fastigiatus. São constatadas variações na morfologia das pétalas, como as elípticas (Fig. 9) em M. frondosus, as espatuladas (Fig. 10) em M. fastigiatus, as obovadas (Fig. 11) em M. leprosus e as lineares (Fig. 12) em $M$. venezuelensis. Ainda, ressalta-se o ápice truncado característico das pétalas de $M$. fastigiatus, bem como a ungüícula menor que $1 \mathrm{~mm}$ compr.; este último caráter também diferencia $M$. leprosus, das demais espécies do gênero, por atingir até $4 \mathrm{~mm}$ compr. e representar as maiores dimensões de ungüícula. Nas demais espécies, a ungüícula mede ca. 1,5mm compr. O único estudo anteriormente realizado para o grupo (Rudd 1972) não havia destacado a morfologia das pétalas como relevantes na diferenciação das espécies. As flores regulares de Myrocarpus sempre em posição ascendente em relação aos pedicelos (Fig. 1-4) sugerem que, no decorrer do desenvolvimento floral, as pétalas se afastam, expondo os verticilos mais internos, androceu e gineceu. Provavelmente, a posição constante das flores em Myrocarpus relaciona-se às várias opções para entrada do polinizador, conforme sugestão de Proctor et al. (1996) para flores com simetria radial. Além disso, a ocorrência de flores não papilionadas em um táxon não implica em caráter plesiomórfico, como até então aceito (Polhill 1981; 1994), ou seja, nos representantes de Papilionoideae com flores regulares, a condição resulta de reversões independentes, a partir de flores zigomorfas típicas, direcionadas para atender à diferentes polinizadores (Pennington et al. 2000). O aroma das flores de $M$. frondosus e $M$. fastigiatus possui como principal componente o nerolidol, responsável não somente pela fragrância destas, bem como pela síntese vitamínica (Schubert et al. 1992).

Androceu - Os filetes são unidos somente na base, aspecto congruente com a delimitação da tribo. Dois comprimentos de filetes são comuns entre as espécies, exceto em M. leprosus com estames isodínamos. As anteras são elípticas com ápice e base obtusos.

Gineceu - O gineceu é estipitado, com revestimento seríceo em $M$. fastigiatus e glabro em $M$. leprosus e $M$. frondosus. O estigma é truncado em $M$. leprosus e puntiforme em M. frondosus e M. fastigiatus. Frutos - As sâmaras são alongadas (Fig. 13), com alas marginais e região seminífera central, com vesículas de bálsamo externamente conspícuas. A ornamentação da região seminífera é escalariforme (Fig. 14) para quatro espécies e areolada (Fig. 15) em M. emarginatus; caráter relevante para a delimitação de uma nova espécie (Sartori \& Tozzi 2001). As sementes são alongadas, estreito-oblongas (Fig. 16), com o ápice truncado e a base assimétrica, e encontram-se inseridas no endocarpo. As características dos frutos em Leguminosae são bastante significativas, embora, Polhill (1981) tenha ressaltado que estas, quando superestimadas, podem levar à segregação de grupos naturais tanto no nível de tribo como de gênero.

Distribuição geográfica: a África representa um centro primário de diversificação das leguminosas tropicais (Raven \& Polhill 1981), enquanto a América tropical de Sophoreae (Herendeen 1992). Apesar da diversidade de Leguminosae, na América do Sul, ocorrem relativamente poucos grupos de gêneros endêmicos e nenhuma concentração notável daqueles mais antigos (Raven \& Polhill 1981). Sophoreae, que representa um dos grupos centrais de radiação de Papilionoideae, possui elementos exclusivamente tropicais. 


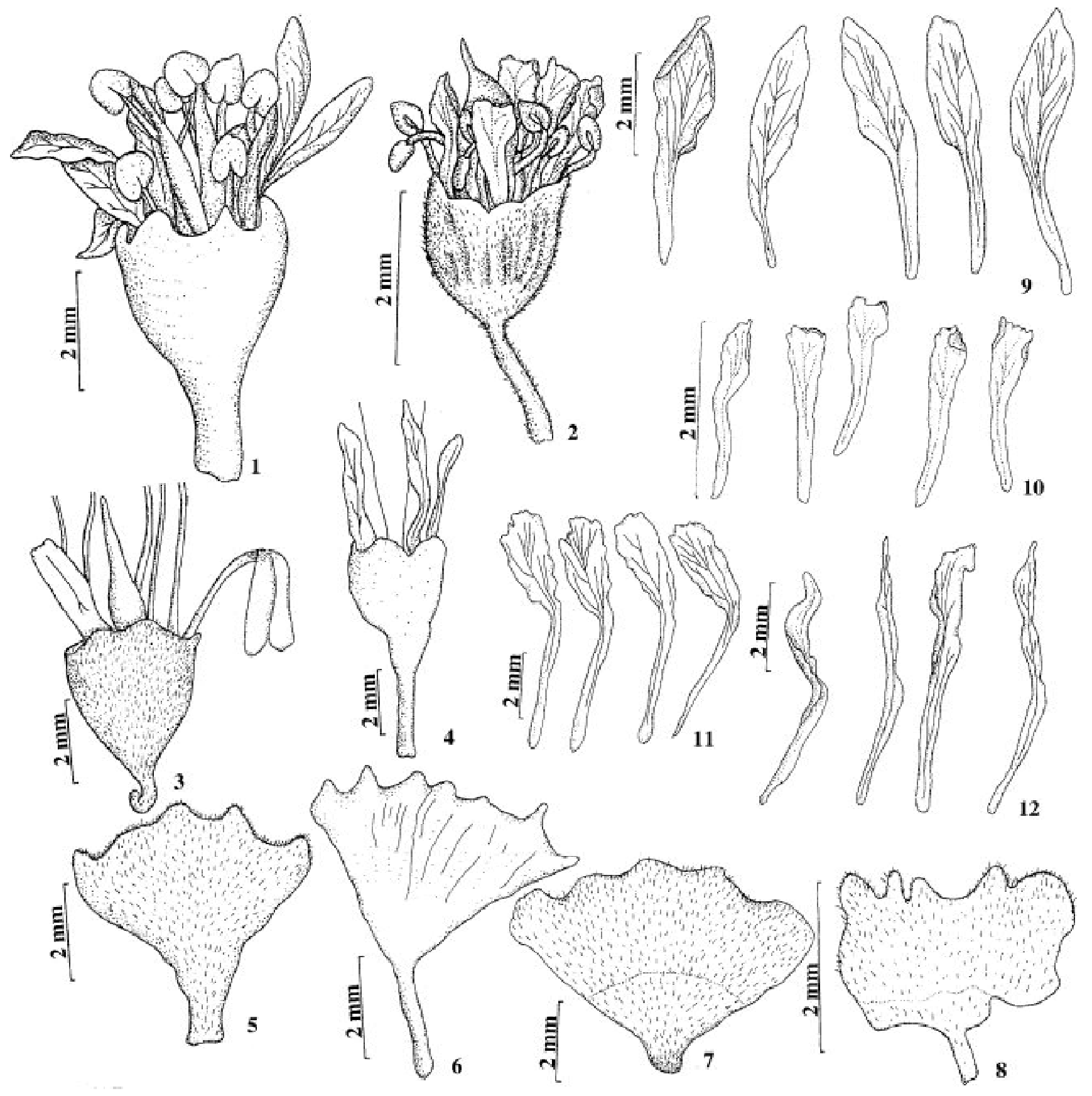

Figuras 1-12. Flores e estruturas florais dos representantes de Myrocarpus. 1-4. Flores regulares: 1. Myrocarpus frondosus. 2. Myrocarpus fastigiatus. 3. Myrocarpus leprosus. 4. Myrocarpus venezuelensis. 5-8. Cálice em secção longitudinal, vista externa: 5. Myrocarpus leprosus. 6. Myrocarpus venezuelensis. 7. Myrocarpus frondosus. 8. Myrocarpus fastigiatus. 9-12. Pétalas evidenciando variação morfológica: 9. Myrocarpus frondosus. 10. Myrocarpus fastigiatus. 11. Myrocarpus leprosus. 12. Myrocarpus venezuelensis. (1, 7, 9: Hatschbach 48383; 2, 8, 10: Santos 2591; 3, 5, 11: Pickel s.n. SP53474; 4, 6, 12: Pires 13169). 


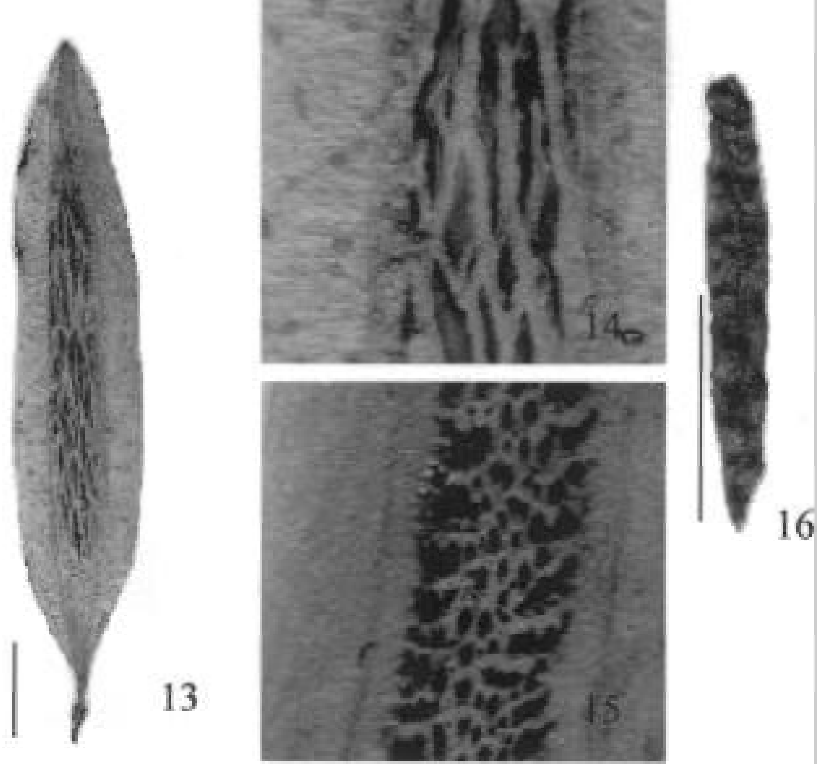

Figuras 13-16. Fruto e semente dos representantes de Myrocarpus. 13. Sâmara com região seminífera central de Myrocarpus fastigiatus. 14. Ornamentação escalariforme da região seminífera de Myrocarpus fastigiatus. (4×). 15. Ornamentação areolada da região seminífera de Myrocarpus emarginatus (3,5×). 16. Semente de Myrocarpus fastigiatus (13, 14, 16: Queiroz \& Santos 3618; 15: Antezana 614). Escala: $1 \mathrm{~cm}$.
Myrocarpus é um gênero exclusivamente sulamericano, cujas espécies ocorrem no norte da América do Sul, no leste da Bolívia e nas Regiões Norte, Sul, Sudeste brasileiras, inclusive na costa atlântica, preferencialmente em florestas; as espécies não ocorrem na Bacia Amazônica nem nos Andes. A única espécie do gênero amplamente distribuída é M. frondosus, que ocorre no sudoeste paraguaio, norte da Argentina e nas Regiões Sul, Sudeste e Nordeste do Brasil. Com ocorrência restrita à costa atlântica, M. fastigiatus estende-se de Pernambuco ao Rio de Janeiro. No Nordeste brasileiro, é uma das espécies que integram as florestas interiores montanas ("brejos" de altitude, Prance 1982; 1987b), sendo tolerantes às temperaturas mais baixas (Bigarella et al. 1975). M. venezuelensis apresenta uma disjunção entre a Venezuela e o norte brasileiro ocorrendo sempre em foresta e eventualmente associada a cursos d'água. M. emarginatus é conhecida, até o momento, somente em Cochabamba, na Bolívia, ocorrendo em bosque mesoandino. M. leprosus possui coletas apenas em Santos, Estado de São Paulo, em encosta de morro e provavelmente está extinta, considerando que seu ambiente foi drasticamente alterado.

Chave para as espécies de Myrocarpus

1. Ápice dos folíolos acuminado

2. Folíolos menores que $6 \mathrm{~cm}$ compr.; pétalas elípticas

3. M. frondosus

2. Folíolos maiores que $6,5 \mathrm{~cm}$ compr.; pétalas lineares ou obovais

3. Fruto maior ou igual a $10 \mathrm{~cm}$ compr.; pedicelo e cálice glabrescentes; pétalas lineares; folíolos longamente acuminados 5. M. venezuelensis

3. Fruto menor que $10 \mathrm{~cm}$ compr.; pedicelo e cálice ferrugíneo-seríceos; pétalas obovais; folíolos brevemente acuminados 4. M. leprosus

1. Ápice dos folíolos obtuso, retuso ou emarginado

4. Folíolos discolores, ápice obtuso e/ou retuso, pontos e listras não impressos na lâmina; fruto com região seminífera escalariforme (Brasil)

4. Folíolos concolores, ápice emarginado, pontos e listras impressos na lâmina; fruto com região seminífera areolada (Bolívia). 1. M. emarginatus

1. Myrocarpus emarginatus A.L.B. Sartori \& A.M.G. Azevedo, Novon 11(3): 353. 2001. Tipo: Bolívia. Cochabamba, Campero baixada Buena Vista, I/1993, fr., C. Antezana 614 (Holótipo: BOLV!; Isótipo: MO!)

Árvore 3-9m alt., ramos quadrangulares, lenticelas inconspícuas. Folhas 7-9-folioladas; pecíolo, raque, peciólulo glabros; pecíolo 2,0-2,7mm compr.; raque 5,0-8,7(-11,2)cm compr.; peciólulo 4,0-4,8mm compr.; folíolo 3,5-4,2×2,6-3,0cm, oblongo, elíptico, às vezes o inferior oval, ápice comumente emarginado, base atenuada, margem reta, inteira, não revoluta, concolores, glaucos, ambas as faces glabras, nervuras conspícuas na face adaxial, pontos e listras translúcidos, conspícuos, impressos na lâmina. Flores não vistas. Sâmaras 5,2-7,7×1,0-1,3cm, amareladas, região seminífera 5-8mm larg., acastanhada, areolada, estipe 5,7-8,0mm compr., base assimétrica, cálice persistente, ápice obtuso, apiculado.

Myrocarpus emarginatus apresenta como características diagnósticas os folíolos glaucos, de ápice 
emarginado, com pontos e listras translúcidos impressos na lâmina e sâmara com a região seminífera areolada (Fig. 15). É próxima de M. fastigiatus, principalmente na forma dos folíolos, porém $M$. fastigiatus apresenta pecíolo não ultrapassando $14 \mathrm{~mm}$ compr., peciólulo com até $3,7 \mathrm{~mm}$ compr. e folíolos com 1,9-3,3×1,0-1,9cm, além da região seminífera escalariforme. M. emarginatus é caracterizada também pelo tipo de cristalóide e de abertura estomática (A.L.B. Sartori comunicação pessoal).

Distribuição e ambiente: ocorre na Bolívia (Fig. 17), Departamento de Cochabamba, província de Campero, em floresta xerofítica, preferencialmente em solo rochoso, juntamente com Neocardenasia herzogiana Backeberg, Schinopsis haenkeana Engler e Cochlospermum tetroporum Hallier f., em altitudes de 1.170 a $2.050 \mathrm{~m}$.

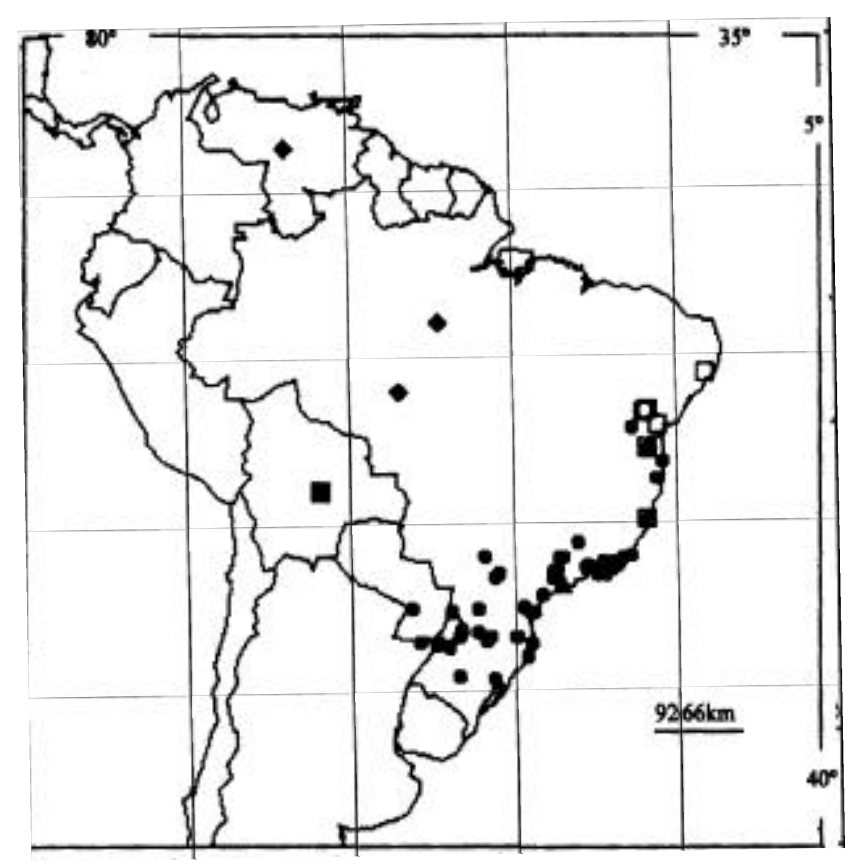

Figura 17. Distribuição geográfica das espécies de Myrocarpus. $\mathbf{\square}=$ M. emarginatus $; \square=$ M. fastigiatus $; \bullet=M$. frondosus $; \square=M$. leeprosus; $\$$ M. venezuelensis.

Flores e frutos coletados nos meses de janeiro e abril.

Nomes populares: quina-quina na Bolívia (C. Antezana 614).

Material examinado: BOLÍVIA. Cochabamba: Cochabamba, Campero, Rio Grande, X/1999, fr., $C$. Antezana 1342 (BOLV); Campero, Bajada Quinarí, Rio Mizque, IV/1999, fr., M. Fernandez 2 (BOLV).
2. Myrocarpus fastigiatus Allemão, Diss. Leg. 26, com ícone, 1847. Tipo: Brasil, Rio de Janeiro, 1860, F.F. Allemão s.n. (Holótipo: R não encontrado; Isótipos: $\mathrm{MO}$ !, F!).

Fig. 18.

Árvore 2,5-7(-25)m alt., ramos cilíndricos, lenticelados. Folhas 7-12-folioladas; pecíolo, peciólulo seríceos a glabros; pecíolo 6-14mm compr.; raque 1,9-6,0cm compr., esparsamente tomentosa; peciólulo 1,2-3,7mm compr.; folíolos 1,9-3,3×1,0-1,9cm, oblongos, elípticos, ápice geralmente obtuso e retuso, raramente emarginado, base atenuada, margem reta, inteira, não revoluta, discolores, face adaxial e abaxial esparsamente seríceas ou glabras, pontos e listras conspícuos, mas não impressos na lâmina. Racemos geminados, fasciculados, axilares, em ramos áfilos, eixos ferrugíneo-tomentosos, menores que as folhas; brácteas lineares, 0,5-0,7 mm compr.; pedicelo esparsamente ferrugíneo-tomentoso, 1,0-1,9mm compr. Flores 2,0-2,5mm compr., amarelo-claras ou brancas; cálice campanulado, 1,6-2,8×1-1,6mm, lacínios obtusos, externamente denso ferrugíneo-tomentosos; pétalas 1,4-3,8 $\times$ ca. $0,4 \mathrm{~mm}$, ungüícula ca. $0,8 \mathrm{~mm}$ compr., espatuladas, ápice truncado, base atenuada, glabras; filetes em dois comprimentos; gineceu $2-4,5 \mathrm{~mm}$ compr., esparso-seríceo, estigma puntiforme. Sâmara $3,5-7,7 \times 0,7-1,5 \mathrm{~cm}$, amarelada ou acastanhada; região seminífera 4-6,4mm larg., acastanhada, escalariforme, estipe $2-4,4 \mathrm{~mm}$ compr., base assimétrica, cálice persistente ou não, ápice obtuso, às vezes, apiculado.

Myrocarpus fastigiatus diferencia-se das demais espécies do gênero, principalmente, pelos folíolos comumente de ápice retuso e das pétalas espatuladas com ápice truncado e base atenuada. A ornamentação escalariforme da região seminífera também pode ser usada para distinguir esta espécie de M. emarginatus.

O número reduzido de espécimes disponíveis para a espécie pode dificultar a pronta identificação destes, quando representam extremos de variação. Segundo Lewis (1987) alguns espécimes coletados na Bahia, identificados como M. fastigiatus, provavelmente corresponderiam a uma nova espécie. A análise das coletas mencionadas por Lewis (1987) além daquelas listadas no material examinado possibilitou o reconhecimento de um único táxon. O gradiente de variações macromorfológicas dos folíolos, flores e frutos não subsidiam o estabelecimento de uma nova espécie devido à sobreposição verificada. Por outro lado, M. fastigiatus caracteriza-se por um conjunto de caracteres micromorfológicos, como mesofilo 


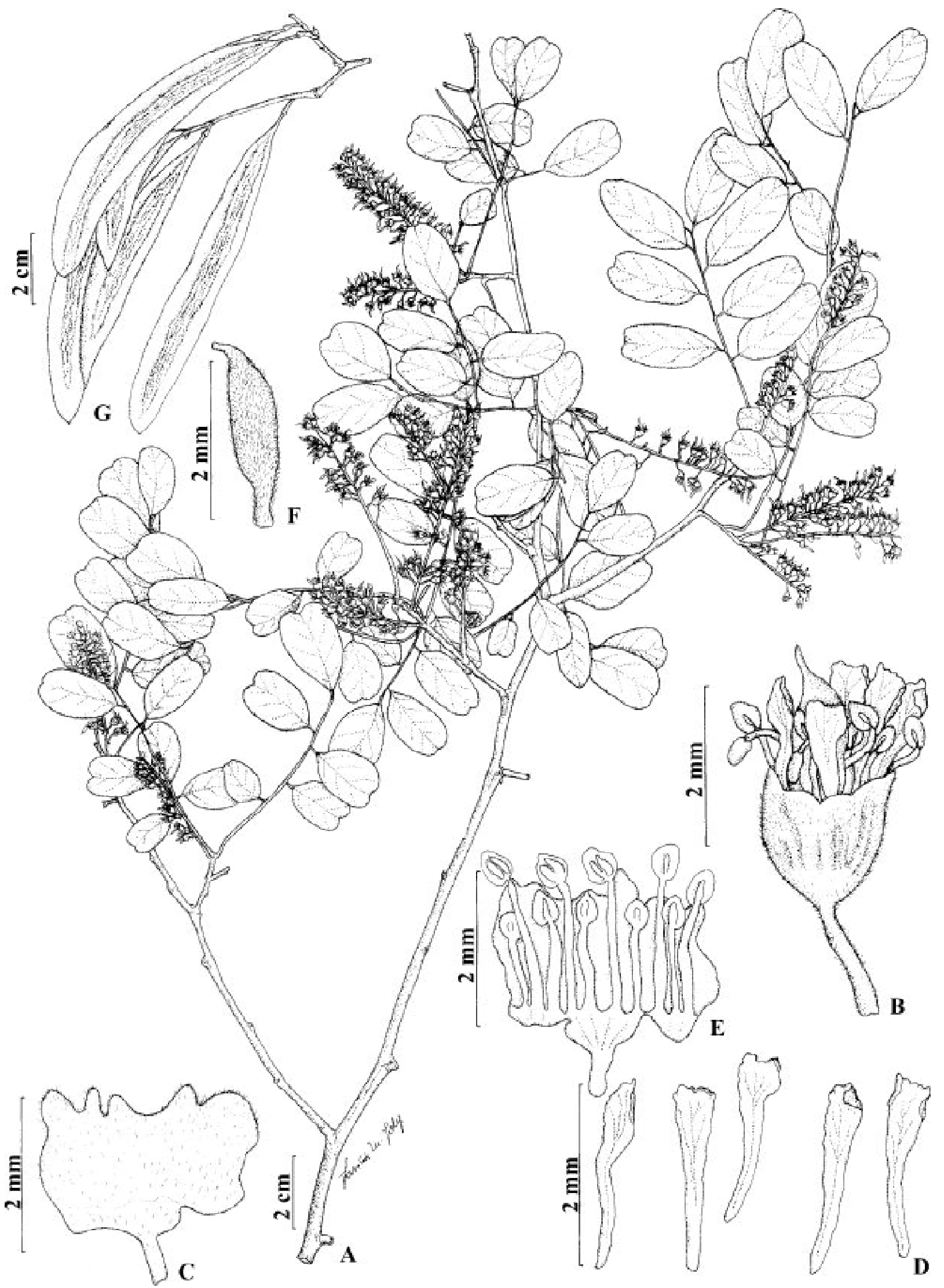

Figura 18. Myrocarpus fastigiatus. A. Ramo com inflorescências. B. Flor. C. Cálice, vista externa. D. Pétalas. E. Cálice, vista interna mostrando androceu e hipanto. F. Gineceu. G. Frutos. (A: Lima 685345, B-F: Santos 2591, G: Andrade-Lima 68-5400). 
homogêneo, hipoderme ausente e células epidérmicas papilosas na lâmina foliolar (Sartori \& Tozzi 2002).

Distribuição e ambiente: endêmica do Brasil com distribuição que se estende do Estado do Rio de Janeiro em floresta ombrófila densa até o de Pernambuco (Fig. 17), onde ocorre em floresta ombrófila densa altomontana.

Floresce de janeiro a abril, em julho e agosto. Frutos constatados somente em junho.

Nomes populares: óleo-pardo (D.A. Folli 214), catureíba (H.J. Saldanha 937) no Brasil.

Material selecionado: BRASIL. Bahia: Boa Nova, II/1973, fl., T.S. Santos 2591 (CEPEC, US); Castro Alves, III/1993, fl., L.P. Queiroz et al. 3087 (HUEFS); Caetité, X/1993, fl., L.P. Queiroz \& N.S. Santos 3639 (CEPEC); Caetité, X/1993, fr., L.P. Queiroz \& N.S. Santos 3618 (HUEFS); Mairi, IX/1980, R. Orlandi 291 (RB); Mundo Novo, V/1973, fl., G. Pinto 1579 (CEPEC); Espírito Santo: Linhares, Reserva Vale do Rio Doce, estrada 154, I/1979, fl., D.A. Folli 214 (CVRD); Pernambuco: Brejão, $15 \mathrm{Km}$ depois de Brejão estrada para Bom Sucesso, VI/1968, fr., Andrade-Lima 68-5400 (F); Brejão, $15 \mathrm{Km}$ depois de Brejão estrada para Bom Sucesso, IV/1968, fl., Andrade-Lima 68-5345 (F); Rio de Janeiro: Mendanha, s.d., J. Saldanha 937 (R); Rio de Janeiro, s.d., fr., A.F.M. Glaziou 5082 (RB); Rio de Janeiro, Morro Carvalhão, s.d., fr., C.A.W. Schwacke 6310 (RB); Santa Cruz, Escola Nacional de Agronomia, IX/1940, L. Djalma \& M. Kuhlman 48 (RB); Serra Grande, Morro do Carvalhão, XII/1871, fl., A.F.M. Glaziou 5826 (R); s.l., Bosque do Roxinho, VII/1937, fl., C. Lage 80816 (US).

3. Myrocarpus frondosus Allemão, Diss. Leg. 22, com ícone, 1848. Tipo: Brasil. Rio de Janeiro, 1860, F.F. Allemão s.n. (Holótipo: R não encontrado; Isótipo: $\mathrm{MO}$ !).

Leptolobium punctatum Benth., Linnaea 22: 526. 1849. Tipo: Brasil, Minas Gerais, A.F. Regnell II.65 1/2 (Holótipo: K, Isótipos: R!, NY!, US).

Myrocarpus paraguariensis Hallier f., Meded. Rijks.-Herb. 27: 40. 1915. Tipo: Paraguai, Cordilheira de los Altos, IX/1902, fl., K. Fiebrig 165 (Holótipo: L!). Myrocarpus frondosus f. paraguariensis (Hallier f.) Hassler, Repert. Spec. Nov. Regni. Veg. 16: 233.1919.

Fig. 19.

Árvore 6-27,5m alt., ramos cilíndricos, raramente quadrangulares, lenticelados. Folhas 5-8-folioladas; pecíolo, raque e peciólulo glabros, às vezes, esparsamente tomentosos; pecíolo 9-20mm compr.; raque $1,7-6,5 \mathrm{~cm}$ compr.; peciólulo $2-4 \mathrm{~mm}$ compr.; folíolos 3,7-5,6×1,3-3,0cm, elípticos ou ovais, ápice acuminado, mucronado, retuso, base atenuada, assimétrica, arredondada, raramente subcordada, margem inteira ou crenada, sinuosa ou reta, não revoluta, discolores, ambas as faces glabrescentes, nervuras conspícuas na face adaxial, pontos e listras translúcidos, conspícuos na lâmina. Racemos simples, geminados, axilares ou terminais, às vezes em ramos áfilos, mais curtos ou mais longos que as folhas, eixos rufo-tomentosos, raramente rufo-seríceos; brácteas deltóides, côncavas, externamente rufo-tomentosas, 0,5-0,8mm compr.; pedicelo e cálice ferrugíneoseríceos; pedicelo 1,5-2mm compr. Flores 2,6-4,0mm compr., brancas ou branco-esverdeadas; cálice campanulado, 2,5-4,0×1,9-3,4mm, lacínios obtusos, raramente agudos; pétalas 4,0-6,3×0,8-1,5mm, ungüícula 1,5-2,6mm compr., elípticas, ápice obtuso, base atenuada, glabras, raramente seríceas; filetes em dois comprimentos; gineceu 3,5-7,0mm compr., glabro, estigma puntiforme. Sâmara 4,2-8,0×0,8-1,8cm, amarelada, região seminífera $3-7 \mathrm{~mm}$ larg., acastanhada, escalariforme, estipe 3-4,6(-6,8)mm compr., base assimétrica, cálice persistente, raramente também estames, ápice agudo, apiculado.

Myrocarpus frondosus é diferenciada de M. venezuelensis e M. leprosus pelos folíolos menores e pétalas elípticas. Os frutos são maiores que os de M. leprosus, porém menores do que aqueles de M. venezuelensis. Dentre as espécies do gênero, $M$. frondosus é a mais polimórfica em relação à forma da base dos folíolos, comprimento relativo e tipo das inflorescências e forma dos lacínios. Folíolos cartáceos foram observados em espécimes do Rio de Janeiro, Paraná, Santa Catarina e Paraguai comumente oriundos de áreas mais úmidas, como mata higrófila, mata pluvial e de encosta. As inflorescências são congestas quando mais curtas que as folhas, sendo comuns principalmente nos espécimes do Paraguai, e quando maiores são laxas e podem ocorrer nos espécimes provenientes dos Estados do Sul e Sudeste do Brasil e da Bahia. O cálice sempre campanulado pode apresentar lacínios obtusos e agudos. As análises anatômicas e da cera epicuticular de vários espécimes confirmaram a existência de um gradiente de variação entre as amostras. Assim, nenhuma categoria infraespecífica pôde ser reconhecida, sendo M. frondosus considerada uma espécie polimórfica, ao nível macro e micromorfológico (Sartori \& Tozzi 2002). 


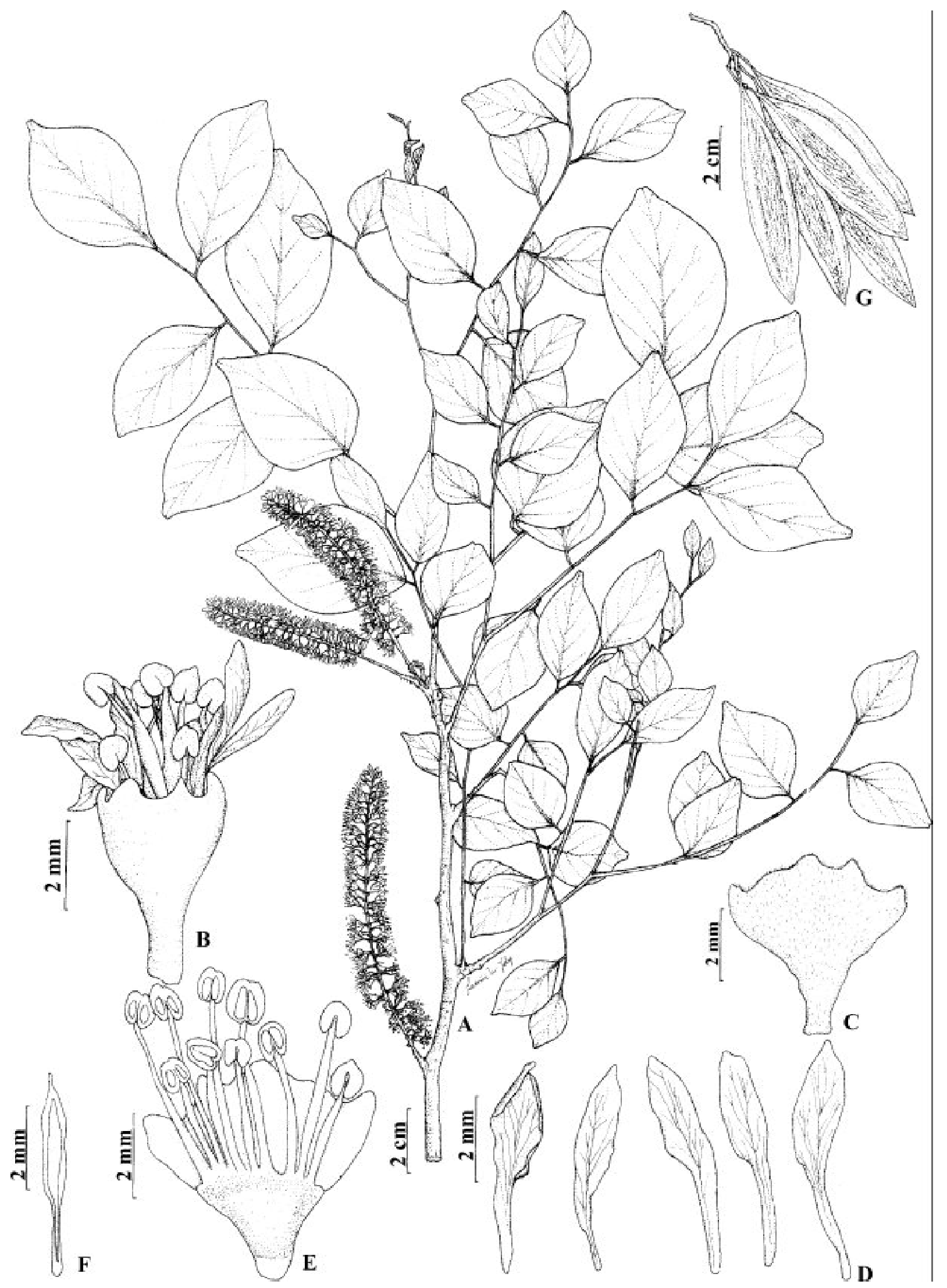

Figura 19. Myrocarpus frondosus. A. Ramo com inflorescências. B. Flor. C. Cálice, vista externa. D. Pétalas. E. Cálice, vista interna mostrando androceu e hipanto. F. Gineceu. G. Frutos (A: Vieira FUEL 3387; B-F: Hatschbach 48383; G: Durigan 1003). 
Distribuição e ambiente - ocorre do sudoeste do Paraguai ao sul da Bahia (Fig. 17). Através da floresta estacional semidecidual submontana, a distribuição de M. frondosus estende-se do sudoeste do Paraguai, norte da Argentina ao interior do Estado de São Paulo. Nesse Estado, através da floresta ombrófila densa atinge os Estados do Rio de Janeiro e do Espírito Santo. Também há registros de sua ocorrência em floresta ombrófila mista alto-montana, no pico do Itatiaia. $\mathrm{Na}$ Bahia, onde $M$. frondosus apresenta seu limite norte de distribuição, ocorre em floresta estacional decidual submontana e em floresta ombrófila densa. Em floresta ombrófila densa, atinge o sul do Brasil, ocorrendo até Porto Alegre. Em Santa Catarina, em altitudes entre 200 a 500m, e no Paraná, até $1.200 \mathrm{~m}$, ocorre em floresta ombrófila mista, comumente associada a cursos d'água.

Coletado material em frutificação em março, junho, e de agosto a dezembro. A análise conjunta do material coletado permite inferir que os espécimes do Rio de Janeiro e da Bahia floresceram de fevereiro a agosto, os de São Paulo e Espírito Santo com início da florada em maio, estendendo-se até novembro, os espécimes do Paraná, Santa Catarina, Rio Grande do Sul, Paraguai e Argentina florescem de agosto até dezembro. A presença concomitante de flores e de frutos é freqüente em um mesmo espécime.

Nomes populares: incienso (A. Krapovickas 15455) na Argentina; sapuvão (J.C. Lindeman \& J.H. Haas 667), cabreúva (R. Reitz \& R. Klein 7246 e 8294, J.C. Lindeman \& J.H. Haas 1003), óleo-pardo (F.C. Hoehne US 2790620, C. Lage 80816, M. Kuhlmann 195, Regnell 11651/2, C. Mello 66488), recoleta (J.G. Jardim et al. 280), brahuna (T.S. Santos 887), brahuna-parda (T.S. Santos 887, A.J. Ribeiro et al. 435), cabore (G. Hatschbach 17812), caboretinga (A.L.B. Sartori et al. 207) no Brasil; incenso (B. Balansa 3112) no Paraguai.

Material selecionado: ARGENTINA. Missiones: São Pedro, II/1907, s.c. s.n. (LP); s.1., VII/1914, Expedição Cunan Pireibo Leon Misiones 684 (F); Cerro Azul, IX/1969, fl., A. Krapovickas et al. 15455 (LP, MO); Iguassú, IX/1996, fl., J. Herrera 197; Iguazú, IX/1917, fl. fr., s.c. s.n. (Her. Gt. Bertoni 150 A, B); Corrientes: Ituzaingô, Rincón, Sta. María, XI/1988, fr., S.G. Tressens et al. 3443 (MO). BRASIL. Bahia: Boa Nova, II/1973, fl., T.S. Santos 2591 (US); Eunápolis, VII/1970, fr., T.S. Santos 887 (US); Eunápolis, X/1994, fr., A.J. Ribeiro et al. 435 (CEPEC); Una, Km 104 rodovia Una-Ilhéus, VIII/1993, fr., J.G. Jardim et al. 257 (MO); Una, Reserva Biológica Mico-leão, IX/1993, fr., J.G. Jardim et al. 280 (MO); Una, Reserva Biológica Mico-leão, VII/1993, fl., J.G. Jardim et al. 218 (MO); Espírito Santo: Conceição do Castelo, XI/1987, fl., G. Hatschbach 50687 \& J.M. Silva (F, MO); Linhares, reserva Vale do Rio Doce, VIII/1996, A.L.B. Sartori et al. 207 (UEC); Presidente Kennedy, São Salvador, 1993, fr., J.M.L. Gomes 7445 (VIES); Minas Gerais: Caldas, 1865, fr., A.F. Regnell s.n. (R, US 1337577); Mucugê, IX/1968, fr., V. Gomes 2813 (RB); Paraná: Bocaiúva do Sul, IX/1994, fl., G. Hatschbach 1994 (UEC); Campina G. Sul, morro Guaricana, XI/1967, fl., G. Hatschbach 17812 (RB, US); Campina Grande do Sul, VIII/1969, fl., C. Koczicki 226 (F, FUEL); Catanduvas, X/1984, fl., G. Hatschbach 48383 (F); Clevelândia, N. do Rio Chopim, s.d., J.C. Lindeman \& J.H. Haas 1003 (U); Ibiporã, III/1990, S.M. Silva et al. s.n. (FUEL 12168); Laranjeira do Sul, IX/1968, fl., G. Hatschbach 19843 (MO); Londrina, X/1986, fl., A.O.S. Vieira s.n. (FUEL 3387); Morretes, IX/1969, fl., G. Hatschbach 22125 (F); Paranaguá, VIII/1951, fl., G. Hatschbach 2480 (LP); s.l., reserva sul do Rio Ivaí 30 KM E. de Cianorte, s.d., J.C. Lindeman \& J.H. Haas 667 (U); Sapopema, IV/1990, F. Chagas \& F.C. Silva s.n. (FUEL 12542); Sertanópolis, IX/1990, fr., M.C. Dias et al. 44 (FUEL); Rio de Janeiro: Campo Belo, s.d., A. Sampaio 4821 (R); Campos, VI/1918, A. Sampaio 3106 (R); Itatiaia, VIII/1925, fl., J.G. Kuhlmann 18992 (RB, US); Itatiaia, estação ecológica, III/1941, fr., W.M. Ramos 250 (RB); Nova Friburgo, VII/1880, fl., A.F.M. Glaziou 11908 (US); Nova Friburgo, Macaé de Cima, X/1990, M.L. Costa et. al. s.n. (CEPEC 61386); Petrópolis, s.d., A.F.M. Glaziou s.n. (R 69643); Petrópolis, Cascatinha, VI/1943, fl., O.C. Goes \& D. Constantino 622 (RB); Rio de Janeiro, s.d., fl., A.F.M. Glaziou 11906 (US); Rio de Janeiro,VI/1928, fl., Pessoal Horto Florestal 473 (RB); Rio de Janeiro, III/1941, fr., W.D. Ramos 250 (RB); Rio de Janeiro, estrada da Gávea, VIII/1927, fl., J.G. Kuhlmann 473 (RB); Rio de Janeiro, morro Dois Irmãos, VI/1921, fl. fr., D. Constantino 16130 (RB); Rio de Janeiro, pico do Itatiaia, IV/1948, fl., C. Mello 66488 (RB); Rio de Janeiro, Serra dos Órgãos,1883, J. Saldanha 5072 (R); Sta. Maria Madalena, VII/1987, fl., H.C. Lima et al. s.n. (RB296085, UEC); Rio Grande do Sul: Santa Rosa, XI/1966, fr., K. Hagelund 4861 (F); São Leopoldo, s.d., J. Dutra 275 (R); Serra do Matador, X/1958, fl., R. Reitz \& R.M. Klein 7246 (U, US); Serra Matador, I/1959, fr., R. Reitz \& R.M. Klein 8291 (US); Sta. Maria, XI/1936, W. Rao 35395 (RB); Santa Catarina: Florianópolis, XI/1971, fl., A. Bresolin 395 
(US); Herval Velho, X/1964, fl., L.B. Smith \& R. Reitz 12417 (F, MO, R, US); Imaruí, VIII/1992, fl., G.M. Hatschbach 1993 (MO); Itapiranga, XI/1964, L.B. Smith \& R. Reitz 12660 (R); Nova Teutônia, X/1943, F. Plaumann 144 (RB); Rafael, Ibirama, X/1953, fl., R. Klein 678 (US); Rio do Sul, XI/1958, fl., R. Reitz \& R.M. Klein 7588 (F); São Miguel d'Oeste, X/1964, fl., L.B. Smith \& R. Reitz 12809 (R); Uruguai, X/1964, fl., L.B. Smith \& R. Reitz 12924 (F, LP, R, US); Xanxerê, X/1964, fl., L.B. Smith \& R. Reitz 12496 (US); São Paulo: Águas da Prata, II/1992, D.V. Toledo Filho \& S.A. Bertoni 26050 (UEC); Amparo, XII/1942, M. Kuhlmann 195 (SP); Areias, V/1958, fl., M. Kuhlmann 4422 (SP); Assis, s.d., fr., G. Durigan 1003 (UEC); Cabreúva, X/1933, fl., F.C. Hoehne s.n. (SP, UEC 84330); Cabreúva, serra do Japi, X/1933, fl., F.C. Hoehne s.n. (US 2790620); Campinas, s.d., fl., J.C. Mello s.n. (F 371079); Sete Barras, Faz. Intervales Base, Saibadela, VIII/1994, fl., M. Galleti et al. 531 (UEC); Iguassú,1862, A.P. Duarte \& E. Pereira 67237 (RB); s.l., bosque do Roxinho, VII/1937, C. Lage 48 (RB); s.l., s.d., fr., F.F. Allemão 1879 (H. J. Miers); s.l., s.d., fl., F.F. Allemão s.n. (H. J. Miers). PARAGUAI. Yaguaron: VIII/1880, fl. fr., B. Balansa 3112 (F, U); Ypacaray, região dos lagos, VIII/1913, fl., E. Hassler $12228(\mathrm{~F}$, US); s.l., IX/1928, fl., P. Jorgensen 3605 (F, MO); s.1., s.d., fl., E. Hassler 7335 (F,US); s.1., XI/1943, fl., C. Pavetti \& T. Royas 8649 (RB); s.l., s.d., fl., E. Hassler s.n. (F 1539510).

4. Myrocarpus leprosus Pickel, Arq. Bot. Estado São Paulo 3(3): 161, t. 41. 1955. Tipo: Brasil, São Paulo, Santos, XI/1949, D.B. Pickel s.n. (Lectótipo, aqui designado: SPSF 3462!; Isolectótipo: SP 53474!).

Fig. 20.

Árvore pequena (Pickel 1955), ramos cilíndricos, lenticelados. Folhas 3-4-folioladas; pecíolo, raque e peciólulo esparsamente seríceos; pecíolo ca. $0,9 \mathrm{~mm}$ compr.; raque ca. $3,0 \mathrm{~cm}$ compr.; peciólulo ca. $3,5 \mathrm{~mm}$ compr.; folíolos ca. $6,5 \times 3,3 \mathrm{~cm}$, elípticos, ovais, ápice acuminado, base atenuada, margem inteira, reta, não revoluta, concolores, ambas as faces glabras, nervuras conspícuas em ambas as faces, pontos e listras translúcidos, pouco conspícuos na lâmina. Racemos axilares, eixos rufo-tomentosos, menores que as folhas; brácteas deltóides, côncavas, externamente rufotomentosas, ca. $0,6 \mathrm{~mm}$ compr.; pedicelo, cálice ferrugíneo-seríceos; pedicelo ca. 1,2mm compr. Flores ca. $6 \mathrm{~mm}$ compr.; cálice campanulado, ca. $4,3 \times 7,4 \mathrm{~mm}$, lacínios obtusos; pétalas 6,8-7,4×1,2-1,5mm, ungüícula 3,5-4mm compr., obovadas, ápice obtuso, base atenuada, glabras; filetes de mesmo comprimento; gineceu ca. 6,5mm compr., esparso-seríceo, estigma truncado. Sâmara ca. $3,4 \times 0,75 \mathrm{~cm}$, amarelada, região seminífera ca. $2,8 \mathrm{~mm}$ larg., acastanhada, escalariforme, estipe ca. $3 \mathrm{~mm}$ compr., base assimétrica, resquícios de cálice, ápice obtuso, apiculado.

Myrocarpus leprosus apresenta folíolos com nervuras conspícuas em ambas as faces, cálice mais largo, estames isodínamos, pétalas obovadas com ungüícula maior que as demais espécies do gênero e frutos não ultrapassando $3,5 \mathrm{~cm}$ compr. Considerando a morfologia dos folíolos e do cálice é mais próxima de M. frondosus, mas difere desta, principalmente, pela forma das pétalas, tipo de androceu, dimensões do cálice e do fruto.

Pickel (1955), ao estalecer M. leprosus, designou uma coleção sintípica, compreendendo dois espécimes contidos em uma mesma exsicata. Neste estudo, designamos o material com flores, coletado por D.B. Pickel s.n. (SPSF3462) como lectótipo, devido às informações do protólogo da espécie e pela importância dos caracteres florais na identificação da mesma.

Distribuição e ambiente - as duas coletas de M. leprosus foram de um mesmo local, provenientes de floresta ombrófila densa (Fig. 17). Foi visitada a localidade tipo, morro de Santa Terezinha em Santos, Estado de São Paulo, porém a área encontra-se bastante perturbada, sem indícios da ocorrência da espécie. Provavelmente, a espécie encontra-se extinta, pois desde a década de 40 não existem novos registros.

Flores em setembro e frutos em novembro.

Material examinado: BRASIL. São Paulo: Santos, IX/1949, fl., D.B. Pickel s.n. (SPSF3462, SP53474); SP, Santos, XI/1949, fr., D.B. Pickel s.n. (SPSF3462, SP53474).

5. Myrocarpus venezuelensis Rudd, Phytologia 23(5): 404. 1972. Tipo: Venezuela, Apure, IV/1968, J.A. Steyermark, G. Bunting, C. Blanco 101748 (Holótipo: US, foto P!; Isótipos: U!, NY, VEN).

Fig. 21.

Árvore 25m alt., ramos cilíndricos, lenticelas inconspícuas. Folhas 7-folioladas; pecíolo, raque e peciólulo glabros; pecíolo ca. $1,7 \mathrm{~cm}$ compr.; raque ca. 7,0cm compr.; peciólulo ca. 3,5mm compr.; folíolos ca. $7,0 \times 2,9 \mathrm{~cm}$, oblongos, ovais, ápice acuminado a longamente acuminado, base atenuada, margem inteira, reta, não revoluta, concolores, glabros, face adaxial brilhante, pontos e listras translúcidos, conspícuos na lâmina. Flores observadas somente em pós-antese, 


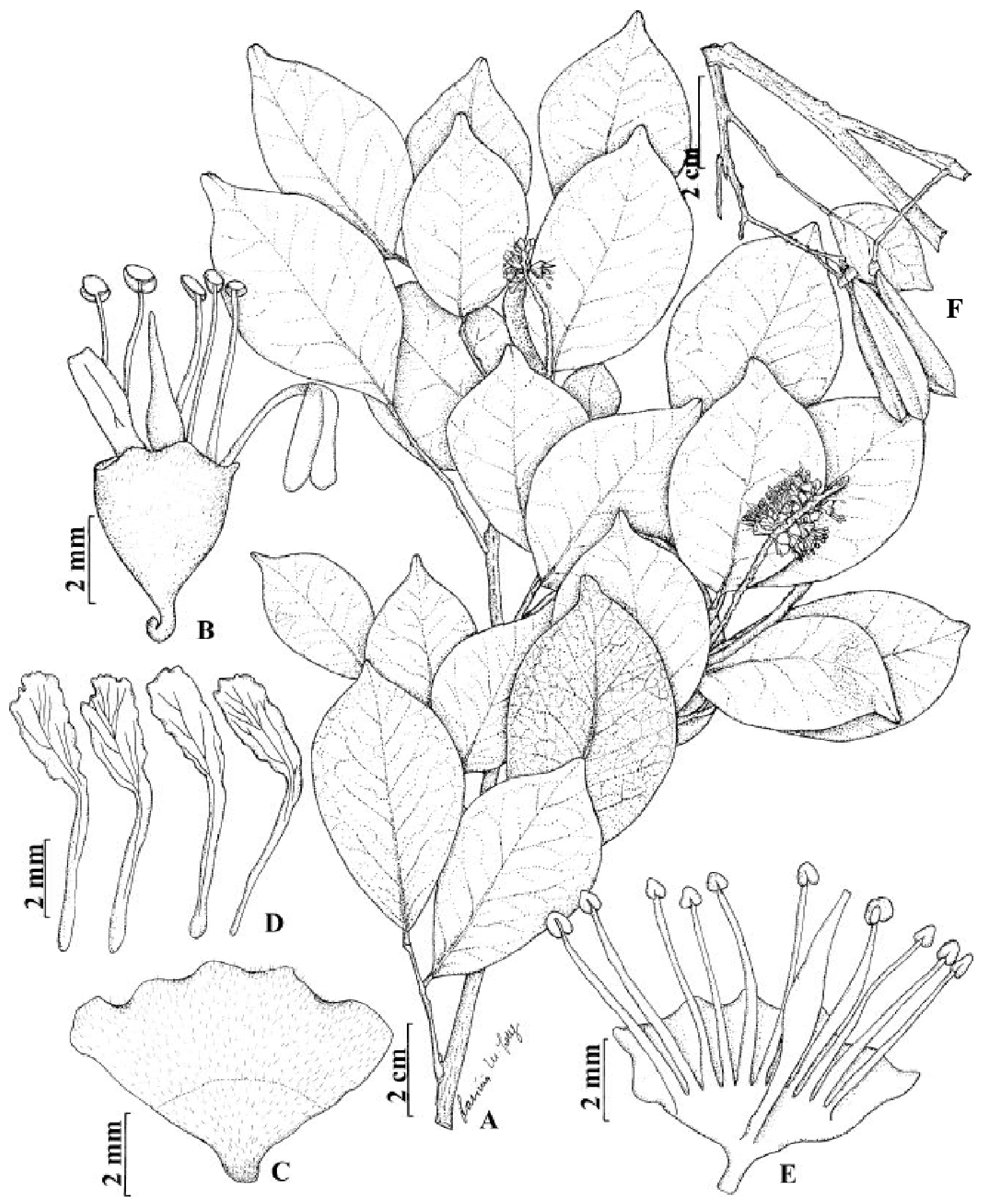

Figura 20. Myrocarpus leprosus. A. Ramo com inflorescência. B. Flor. C. Cálice, vista externa. D. Pétalas. E. Cálice, vista interna mostrando androceu e gineceu. F. Frutos (A-F: Pickel s.n. SP53474). 


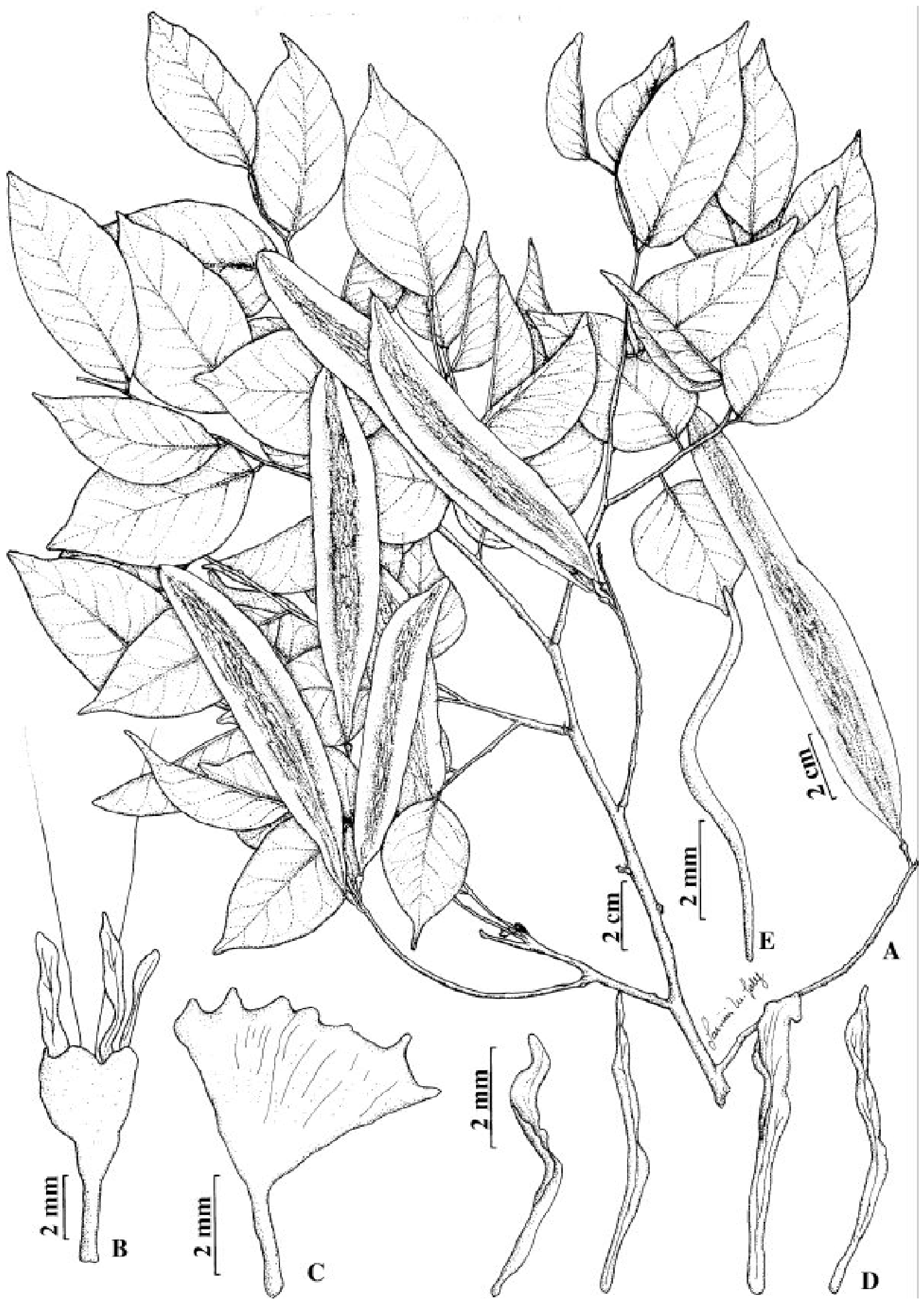

Figura 21. Myrocarpus venezuelensis. A. Ramo com frutos. B. Flor. C. Cálice, vista externa. D. Pétalas. E. Gineceu. (A: Steyermark et al. 101748, B-E: Pires 13169). 
início de frutificação. Pedicelo e cálice glabrescentes; pedicelo ca. 2,2mm compr. Cálice campanulado, ca. $3,8 \times 5 \mathrm{~mm}$, lacínios agudos e obtusos, pétalas $5-6 \times 0,3-0,5 \mathrm{~mm}$, ungüícula ca. $1,6 \mathrm{~mm}$ compr., lineares, ápice obtuso, base atenuada, glabras; gineceu glabro; androceu não observado. Sâmara ca. $10,3 \times 1,8 \mathrm{~cm}$, amarelada, região seminífera ca. $5,7 \mathrm{~mm}$ larg., acastanhada, escalariforme, estipe ca. 4,8mm compr., base assimétrica, com restos de cálice, ápice obtuso, apiculado.

Myrocarpus venezuelensis é a única espécie do gênero com folíolos e frutos maiores que $7,0 \mathrm{~cm}$ e $10,0 \mathrm{~cm}$ compr., respectivamente. Tais caracteres são os principais na sua diferenciação, considerando inclusive $M$. frondosus. Nas flores em pós-antese, o cálice e o pedicelo são glabros e as pétalas lineares. Em termos micromorfológicos a configuração da abertura estomática e o aspecto da superfície foliolar (A.L.B. Sartori, comunicação pessoal) podem também ser utilizados no reconhecimento desta espécie.

Distribuição e ambiente - ocorre na Venezuela e no norte do Brasil (Fig. 17). Foi encontrada preferencialmente em floresta, sendo que na Venezuela pode ocorrer em altitudes entre 250 a 280m; no Pará está associada a cursos d'água e, em Mato Grosso, ocorre em floresta estacional semidecidual submontana (Prance 1987a). A distribuição desta espécie é descontínua, provavelmente relacionada à escassez de coletas na região.

Início de frutificação entre julho e outubro e frutos maduros em abril.

Nomes populares: barbasco (J.A. Steyermark 101748); roxinho (J.M. Pires \& M.R. Santos 16489) na Venezuela; cabreúva (J.M. Pires \& M.R. Santos 16616), condurú-de-sangue (J.M. Pires \& M.R. Santos 13169) no Brasil.

Material examinado: BRASIL. Mato Grosso: Sararé, perto Campo Base do Radambrasil,VIII/1978, fr., J.M. Pires \& M.R. Santos 16616 (M, US); Sararé, perto Campo Radambrasil,VIII/1978, fr., J.M. Pires \& M.R. Santos 16489 (F, MO, NY, RB); Pará: Rio Itacaunas, serra Bevitirama, X/1970, fr., J.M. Pires 12709 (RB); Pará, serra norte, km 3, VII/1973, fr., J.M. Pires \& B.C. Passos 13169 (RB).

\section{Agradecimentos}

À CAPES, pela concessão de bolsa de Doutorado à primeira Autora; aos curadores dos herbários, pelo empréstimo do material solicitado; às pesquisadoras Velva E. Rudd (in memorian) e Ana Odete Vieira, pelo envio de bibliografias; ao Dr. Luciano P. de Queiroz e aos assessores, pelas sugestões; a Sra. Lavínia M. Joly, pelo auxílio no acabamento das ilustrações.

\section{Referências bibliográficas}

Allemão, F.F. 1847. Leguminosa. Myrocarpus fastigiatus. Dissertacion Leguminosae. Typographia do Archivo Medico Brasileiro, Rio de Janeiro.

Bigarella, J.J.; Andrade-Lima, D. \& Riehs, P.J. 1975. Considerações a respeito das mudanças paleoambientais de algumas espécies vegetais e animais no Brasil. Annais da Academia Brasileira Ciências 47: 413-464.

Bridson, G.D.R. \& Smith, E.R. 1991. Hunt Institute for Botanical Documentation. Carmegie Mellon University, Pittsburg.

Greuter, W.; Chairman, F.R.B.; Burdet, H.M.; Chaloner, W.G.; Demolin, V.; Hawksworth, D.L.; Jorgensen, P.M.; Nicolson, D.H.; Silva, P.C. \& Trehane, P. 1994. Internacional Code of Botanical Nomenclature. Koeltz Scientific Books, Königstein.

Herendeen, P.S. 1992. The fossil history from the Eoceno of southeastern North America. v.4. Pp. 85-160. In: P.S. Herendeen \& D.L. Dilcher (eds.). Advances in Legume Systematics, the Fossil Record. Royal Botanic Gardens, Kew.

Holmgren, P.K.; Holmgren, N.H. \& Barnett, L.C. 1990. Index Herbariorum. v.1. The herbaria of the world. New York Botanical Garden, New York.

Lawrence, G.H.M. 1971. Taxonomy of vascular plants. Macmillan, New York.

Lawrence, G.H.M.; Günther; B.; Daniels, G.S. \& Dolezal, A. 1971. Hunt Institute for Botanical Documentation. Hunt Botanical Library, Pittsburg.

Lewis, G.P. 1987. Legumes of Bahia. Royal Botanic Gardens, Kew.

Pennington, R.T.; Klitgaard, B.B.; Ireland, H. \& Lavin, M. 2000. New insights into floral evolution of basal Papilionoideae from molecular phylogenies. v.9. Pp. 233-248. In: P.S. Herendeen \& A. Bruneau (eds.). Advances in Legume Systematics. Royal Botanic Gardens, Kew.

Pickel, B.J. 1955. Uma espécie nova de Myrocarpus (Leg. Pap.). Archivos de Botanica do Estado de São Paulo 3(3): 161-163.

Polhill, R.M. 1981. Sophoreae. v.1. Pp. 213-230. In: R.M. Polhill \& P.H. Raven (eds.). Advances in Legume Systematics. Royal Botanic Gardens, Kew.

Polhill, R.M. 1994. Classification of the Leguminosae. Pp. 35-50. In: F.A. Bisby; J. Buckingham \& J.B. Harbone (eds.). Phytochemical Dictionary of the Leguminosae. Chapman \& Hall, New York.

Prance, G.T. 1982. A review of the phytogeographic evidences for pleistocene climate changes in the neotropics. Annals of Missouri Botanical Garden 69: 594-624. 
Prance, G.T. 1987a. Vegetation. Pp. 28-44. In: T.C. Whitmore \& G.T. Prance. Biogeography and Quaternary History in Tropical America. Clarendon Press, Oxford.

Prance, G.T. 1987b. Biogeography of neotropical plants. Pp. 46-65. In: T.C. Whitmore \& G.T. Prance. Biogeography and Quaternary History in Tropical America. Clarendon Press, Oxford.

Proctor, M.; Yeo, P. \& Lack, A. 1996. The diversity of insectpollinated flowers. Pp. 144-186. In: S.A. Corbet; S.M. Walters; R. Werst; D. Streeter \& D.A. Ratcliffe (eds.). The Natural History of Pollination. Harper Collins Publishers, London.

Radford, A.E.; Dickinson, W.C.; Massey, J.R. \& Bell, C.R. 1974. Vascular Plants Systematics. Harper \& Row, New York.

Raven, P.H. \& Polhill, R.M. 1981. Biogeography of the Leguminosae. v.1. Pp. 27-34. In: R.M. Polhill \& P.H. Raven (eds.). Advances in Legume Systematics. Royal Botanic Garden, Kew .
Rudd, V.E. 1972. A new species of Myrocarpus (Leguminosae) and a brief resume of the genus. Phytologia 23(5): 401-404.

Sartori, A.L.B. \& Tozzi, A.M.G.A. 2001. Myrocarpus emarginatus (Leguminosae, Papilionoideae, Sophoreae), a new species from Bolivia. Novon 11(3): 353-355.

Sartori, A.L.B. \& Tozzi, A.M.G.A. 2002. Comparative leaflet anatomy in Myrocarpus Allemão, Myroxylon L.f. and Myrospermum Jacq. (Leguminosae-PapilionoideaeSophoreae) species. Botanical Journal of the Linnean Society 140: 249-259.

Schubert, V.; Dietrich, A.; Ulrich, T. \& Mosandl, A. 1992. The stereoisomers of nerolidol: separation, analysis and olfatoric properties. Zeitschrift Fuer Naturforschung Section Biosciences 47c: 304-307.

Stearn, W.T. 1973. Botanical Latin. Redwood Press Limited Trowbridge, Wiltshire.

Veloso, H.P. 1992. Sistema Fitogeográfico. Pp. 12-34. In: V.R. dos Anjos (ed.). Manual Técnico da Vegetação Brasileira. IBGE, Rio de Janeiro. 